\title{
COVID-19: Targeting the cytokine storm via cholinergic anti- inflammatory (Pyridostigmine)
}

\author{
Ahmed H Osman* \\ Department of Pathology, Faculty of Veterinary Medicine, Cairo University, Egypt
}

\section{Abstract}

Background: The development of COVID-19 having been set apart as the third presentation of an exceptionally pathogenic coronavirus into the human populace after the extreme intense SARS-COV and MERS-COV in the twenty-first century. The infection itself doesn't make a crucial commitment to mortality, anyway "cytokine storm" created by the unreasonable invulnerable reaction activated by the virus can result in a hyperinflammatory response of lung tissues and deadly lung injury, and in this way increment death rate. In this manner, immunomodulatory medications ought to likewise be remembered for treatment of COVID-19.

Presentation of the hypothesis: the virus particles invade the respiratory mucosa firstly and infect other cells, triggering a series of immune responses and the production of cytokine storm in the body, which may be associated with the critical condition of COVID-19 patients. Once a cytokine storm is formed, the immune system may not be able to kill the virus, but it will certainly kill many normal cells in the lung, which will seriously damage the of lung function. Patients will have respiratory failure until they die of hypoxia. It is not yet clear what the death rate of Covid-19 will be, though the best estimate right now is that it is around 1 percent, 10 times more lethal than seasonal flu due to cytokines storm which trigger a violent attack by the immune system to the body, cause acute respiratory distress syndrome (ARDS) and multiple organ failure, and finally lead to death in severe cases of COVID-19 infection. Therefore, inhibiting cytokine storm can significantly reduce inflammatory injury in lung tissues.

Pyridostigmine (PDG), cholinergic anti-inflammatory pathway (CAP) is a neural mechanism that modulates inflammation through the release of acetylcholine (ACh), resulting in decreased synthesis of inflammatory cytokines such as TNF- $\alpha$ and IL-1. This finding emphasis, the nervous and immune systems work collaboratively during infection and inflammation.

Implications of the hypothesis: Administrations of Pyridostigmine (PDG) as cholinergic agonist inhibits the inflammatory response and lower the mortality of COVID-19 patients. Likewise, activation of the CAP during systemic inflammation down-regulates the production and release of inflammatory cytokines.

\section{Introduction}

COVID-19 is a sort of viral pneumonia with an extraordinary flare-up in Wuhan, China, in December 2019, which is incited with the guide of outrageous intense respiratory disorder coronavirus SARS-CoV-2 [1]. COVID-19 is characterized by a variety of symptoms, including fever, cough, dyspnea, and myalgia in most cases. In severe cases, bilateral lung involvement with ground-glass opacity is the commonest chest CT finding [2]. Almost like the 2002/2003 outbreak of SARS, the severity of COVID-19 disease is related to increasing age and/or comorbidity, although the severe disease is not limited to those risk groups.

\section{More Information}

*Address for Correspondence: Ahmed H Osman, Department of Pathology, Faculty of Veterinary Medicine, Cairo University, Egypt, Tel: 20235676105; 002010977654; Email: ahosman2007@hotmail.com

Submitted: 09 May 2020

Approved: 20 May 2020

Published: 21 May 2020

How to cite this article: Osman AH. COVID-19: Targeting the cytokine storm via cholinergic antiinflammatory (Pyridostigmine). Int J Clin Virol. 2020; 4: 041-046.

\section{DOI: 10.29328/journal.ijcv.1001014}

Copyright: @ 2020 Osman AH. This is an open access article distributed under the Creative Commons Attribution License, which permits unrestricted use, distribution, and reproduction in any medium, provided the original work is properly cited.

Keywords: COVID-19; Cytokine storm; Cholinergic anti-inflammatory pathway; Pyridostigmine

A) Check for updates OPEN ACCESS 
the identification and treatment of hyper-inflammatory reaction using existing; approved therapies with proven safety profiles to deal with the immediate got to reduce the rising mortality. The cholinergic anti-inflammatory pathway (CAP) may be a neural mechanism that modulates inflammation through the discharge of acetylcholine (ACh), leading to decrease synthesis of inflammatory cytokines like TNF- $\alpha$ and IL-1 [5].

\section{Human coronavirus origins}

SARS-COV emerged in humans in 2002 and efficient human to human transmission resulted during a global SARS epidemic which lasted 8 months. During the period of infection, there were 8,098 reported cases of SARS and 774 deaths. This means the virus killed about 1 in 10 people who were infected. [6]. Initial studies investigating animal sources of the virus from "wet markets" within the Guangdong of China suggested that Himalayan palm civets and raccoon dogs were the foremost likely hosts liable for human transmission [7]; however, the role of bats because the original animal reservoir hosts of SARS-COV was speculated as similar viruses were detected in them $[8,9]$. Years later, during ecological surveillance of bats within the same region, a SARS-like COV that closely matched the human SARS-COV was isolated from the Chinese horseshoe bat. However, the precise mechanism by which the zoonotic transmission event to humans occurred remains not clear. Retrospective studies have found low levels of seroprevalence of SARS-like COV in healthy individuals in Hong Kong dating back to 2001. Interestingly, in 13 of 17 of those seropositive patients, the antibodies responded more strongly against the SARS-like-COV isolated from a Himalayan palm cat compared to the human SARS-COV isolate [10]. These data suggest that low levels of human exposure to zoonotic SARS-like COVs occurred before the SARS-COV epidemic that began in 2002 but went unidentified.

MERS-COV emerged in Saudi Arabia in 2012 and continues to cause human disease [11]. Dromedary camels are a natural reservoir host for MERS-COV. MERS-COV has been successfully isolated and cultured from camel specimens [12]. Approximately 55\% of primary MERS-COV cases are results of direct contact with dromedary camels or camel products [13]; however, the rest of primary MERS-COV cases haven't any history of contact with camels or infected individuals and thus, where they came into contact with the virus is unknown. At the end of November 2019, a total of 2494 laboratoryconfirmed cases of Middle East respiratory syndrome (MERS), including 858 associated deaths (case-fatality rate: 34.4\%) were reported globally; the majority of these cases were reported from Saudi Arabia (2102 cases, including 780 related deaths with a case-fatality rate of $37.1 \%$ [11].

In December 2019, a cluster of pneumonic cases caused by a newly identified $\beta$-coronavirus occurred in Wuhan, China. This coronavirus was initially named because of the 2019- novel coronavirus 2019-nCoV) on 12 January 2020 by World Health Organization (WHO).

WHO officially named the disease as coronavirus disease 2019 (COVID-19) and Coronavirus Study Group (CSG) of the International Committee proposed to call the new coronavirus as SARS-CoV-2, both issued on 11 February 2020? The Chinese scientists rapidly isolated a SARS-CoV-2 from a patient within a brief time on 7 January 2020 and came bent genome sequencing of the SARS-CoV-2 [14]. As of 1 March 2020, a complete of 79,968 cases of (COVID-19) is confirmed in China including 2873 deaths [15].

\section{Clinical symptoms}

Illness with COVID-19 has ranged from mild to severe. A recent study found that the common clinical manifestations included fever (88.7\%), cough (67.8\%), fatigue (38.1\%), and sputum production (33.4\%), shortness of breath (18.6\%), pharyngitis (13.9\%), and headache (13.6\%) [2]. In addition, a few patients manifested gastrointestinal symptoms, with diarrhea (3.8\%) and vomiting (5.0\%). Fever and cough were the dominant symptoms whereas upper respiratory symptoms and gastrointestinal symptoms were rare, suggesting the differences in viral tropism as compared with SARS-COV [16], MERS-COV [17], and influenza [18]. The elderly and people with underlying disorders (i.e., hypertension, chronic obstructive pulmonary disease, diabetes, and cardiovascular disease), developed rapidly into acute respiratory distress syndrome even resulting in the death [19].

\section{Coronavirus replication}

Coronavirus is single-stranded RNA virus, about 120 nanometers in diameter. Their resemblance to the sun with a corona, as seen during an eclipse, is thanks to so-called spike glycoproteins, or peplomers, on the surface, which enable coronaviruses to enter host cells. SARS-CoV-1 and SARSCoV-2, which share about $80 \%$ structural identity, do that by harnessing the action of the angiotensin-converting enzyme, ACE-2, which is expressed within the membranes of many cells within the body, including lung alveolar epithelial cells. SARS-CoV19 isolated from the bronchoalveolar lavage fluid of the patient [1].

The virion S-glycoprotein on the surface of coronavirus can attach to the receptor, ACE2 on the surface of human cells [20]. S glycoprotein includes two subunits, S1 and S2 [21]. S1 determines the virus-host range and cellular tropism with the key function domain, while S2 mediates virus-cell membrane fusion by two tandem domains (HR1) [22] and HR2 [23]. After membrane fusion, the viral genome RNA is released into the cytoplasm, and therefore, the uncoated RNA translates two polyproteins, pp1a and pp1ab [24], which encode nonstructural proteins, and form replication-transcription complex (RTC) in double-membrane vesicle [25]. Continuously (RTC) replicates and synthesize a nested set of sub-genomic 
RNAs [26], which encode accessory proteins and structural proteins. Mediating endoplasmic reticulum (ER) and Golgi [27], newly formed genomic RNA, nucleocapsid proteins, and envelope glycoproteins assemble and form viral particle buds. Lastly, the virion-containing vesicles fuse with the cell wall to release the virus. Thus, in COV 19 pathogenesis, reninangiotensin signaling (RAS) acts as a double edge sword, as a receptor for the virus entry and a negative regulator for severe symptoms of infection and lung injury [28, 29].

\section{Immune responses induced by COVID-19 infection}

Cytokines are small molecules of proteins, peptides, or glycoproteins, produced as soluble factors by a spread of distinct cells, including all cells of the body system, also as endothelial, epithelial, and stromal cells [30]. Cytokines are involved in nearly every response to immunity, inflammation, and infection stimuli. Their function is triggered in such processes as proliferation, chemotaxis, mediation of inflammatory responses, homeostasis, differentiation, elimination of pathogens, and necrobiosis [31]. During the incubation and non-severe stages, a selected adaptive immune reaction is required to eliminate the virus and to preclude disease progression to severe stages.

Genetic differences are well-known to contribute to individual variations within the immune reaction to pathogens. However, when a protective immune reaction is impaired, the virus will propagate and massive destruction of the affected tissues will occur, especially in organs that have high ACE2 expression, like intestine and kidney. The damaged cells induce within the lungs that are largely mediated by proinflammatory macrophages and granulocytes.

Lung inflammation is the main explanation for lifethreatening respiratory disorders at a severe stage [4] Alarmingly, after discharge from the hospital, some patients remain/return viral positive even relapse. This means that a virus-eliminating immune reaction to SARS-CoV-2 could also be difficult to induce at least in some patients. Scientists and clinicians have learned much of COVID-19, and its pathogenesis [1]: not all people exposed to SARS-CoV-2 are infected and not all infected patients develop severe respiratory illness. Accordingly, SARSCoV-2 infection can be roughly divided into three stages: stage I, an asymptomatic incubation period with or without detectable virus; stage II, non-severe symptomatic period with the presence of virus; stage III, severe respiratory symptomatic stage with high viral load [32].

\section{Dynamic of a cytokine storm}

Hence, virus-cell interactions produce a various set of immune mediators against the invading virus [33]. Natural immunity is required during a precise regulation to eliminate the virus; otherwise it will end in immunopathology. Plasma cytokines and chemokines were observed ascended in COVID-19 patients, including IL-1, IL-2, IL-4, IL-7, IL-10, IL-
12, IL-13, IL-17, GCSF, macrophages colony-stimulating factor (MCSF), IP-10, MCP-1, MIP- $1 \alpha$, IFN- $\gamma$ and TNF- $\alpha[19,34,35]$.

Collectively, the virus particles invade the respiratory mucosa firstly and infect other cells, triggering a series of immune responses and therefore the production of cytokine storm within the body, which can be related to the critical condition of COVID-19 patients. I'm suggesting that mortality could be thanks to virally driven hyperinflammation. One among the most mechanisms for (ARDS) is that the cytokines storm, the deadly uncontrolled systemic inflammatory response resulting from the discharge of huge amounts of pro-inflammatory cytokines (IFN- $\alpha$, IFN- $\gamma$, IL-1 $\beta$, IL-6, IL-12, IL-18, IL-33, TNF- $\alpha$, TGF $\beta$, etc.) and chemokines (CCL2, CCL3, CCL5, CXCL8, CXCL9, CXCL10, etc.) by immune effectors cells in SARS-COV infection [19,36,37]. Almost like those with SARS-COV, individuals with severe MERS-COV infection show elevated levels of IL-6, IFN- $\alpha$, and CCL5, CXCL8, CXCL-10 in serum compared to those with the mild-moderate disease [38].

The cytokines storm will trigger a violent attack by the immune system, cause ARDS and multiple organ failure, and eventually cause death in severe cases of SARS-CoV-2 infection, a bit like what occurs in SARS-COV and MERS-COV infection [39].

\section{Histopathological finding of COVID-19}

Histologically, the lung is an organ composed of quite 40 differing types of cells [40]. Alveolar epithelial cells (or pneumocytes) are irreplaceable in their important role in lung homeostasis. The ends of the respiratory tree, the lung alveoli, are lined with two sorts of alveolar epithelial cells: type I (AECI), also referred to as pneumocytes type I; and alveolar epithelial cells type II (AECII), also referred to as pneumocytes type II. Type I pneumocytes cover $90-95 \%$ of the alveolus. AECI is squamous, extremely flattened epithelial cells that form an entire, thin lining. These flat cells are liable for oxygen and $\mathrm{CO} 2$ exchange between the airspace and therefore the underlying capillaries and express protein transport that maintains fluid homeostasis. Against this, AECII covers just $7 \%$ of the entire alveolar surface. Pneumocytes type II is typical cuboidal granular cells. They contain lamellar bodies in their cytoplasm that synthesize and secrete such pulmonary surfactant and immunomodulatory molecules as products of the complement system, cytokines, lysozymes, and surfactant proteins (SPs) SP-A and SP-D (C-type lectins) involved in host defense. AECII is liable for epithelium repair. They function as stem cells for type I cell and may repopulate type I after insult $[41,42]$.

Tissue samples from the lung, liver, and heart tissue of the patient histologically showed bilateral diffuse alveolar damage with cellular fibro-myxoid exudate. The proper lung showed evident desquamation of pneumocytes and hyaline membrane formation, indicating acute respiratory distress syndrome. The left lung tissue displayed pulmonary 
edema with hyaline membrane formation, implication early-phase ARDS. Interstitial mononuclear inflammatory infiltrates, dominated by lymphocytes, was seen in both lungs. Multinucleated syncytial cells with atypical enlarged pneumocytes Characterized by large nuclei, amphophilic granular cytoplasm, and prominent nucleoli were identified within the intra-alveolar spaces, showing viral cytopathiclike changes. No obvious intra-nuclear or intra-cytoplasmic viral inclusions were identified. The pathological features of COVID-19 greatly resemble those seen in SARS and Middle Eastern respiratory syndrome (MERS) coronavirus infection. Additionally, the liver biopsy specimens of the patient with COVID-19 showed moderate micro-vesicular steatosis and mild lobular and portal activity, indicating the injury could are caused by either SARS-CoV-2 infection or drug-induced liver injury. There have been a couple of interstitial mononuclear inflammatory infiltrates, but no other substantial damage within the heart tissue [43-45].

\section{Treatment}

The above studies indicate that through inhibiting cytokine activation, excessive inflammatory reaction in lung tissues induced by SARS-CoV-2 can be inhibited, and as a result, lung tissue injury can be mitigated, and the mortality can be reduced. The children always experience mild-moderate clinical illness, elderly individuals exhibit worse outcomes after infection with SARS-CoV-2, further indicating that mature excessive immune reaction towards these pathogenic human coronavirus infections play a key role in inducing severe pulmonary syndrome and even organ failure. Specific new drugs targeted SARS-CoV-2 may take an extended time to evaluate and develop. At this critical moment, several marketed drugs to focus on the inflammatory storm and reduce immunopathology might be considered. The cholinergic anti-inflammatory pathway (CAP) may be a neural mechanism that modulates inflammation through the discharge of acetylcholine (ACh), leading to decreased synthesis of inflammatory cytokines like TNF- $\alpha$ and IL1 [46].

The mechanisms underlying CD4+ T-cell lymphopenia in patients infected with SARS-CoV-2 are incompletely understood. Nonetheless, persistent immune activation, observed even in patients with suppressed viral replication, is considered a critical factor for CD4+ T-cell depletion [47]. Variety of pharmacological strategies, including hydroxychloroquine, statins, cyclosporine A, mycophenolic acid, and rapamycin, have unsuccessfully tried to enhance the cellular response as HIV patients $[47,48]$. Pyridostigmine act as immune modulator is a reversible acetylcholinesterase inhibitor that is FDA-approved for treating myasthenia gravis and reversing the effects of muscle relaxants. It has also been used in the military as a pretreatment for exposure to the chemical nerve agent Soman. Pyridostigmine works by inhibiting the acetylcholinesterase (AChE) enzyme from breaking down the neurotransmitter acetylcholine (ACh), and thereby increases the bioavailability of (Ach) and enhances the transmission of nerve impulses at neuromuscular junctions. In a previous report, Pyridostigmine (PDG) is able to modulate T-cell activation as reflected by cytokine production and cell proliferation in patients with HIV infection [49]. Supported those findings, we hypothesized that T-cell modulation through enhanced (Ach) availability could improve CD4+ T-cell counts in patients with HIV infection that had done not accomplish adequate immune reconstitution. The nervous system senses cytokines and other inflammatory signals and responds, through an anti-inflammatory reflex, via the vagus. Accordingly, electrical stimulation of the vagus, or administration of cholinergic agonists, inhibit the inflammatory response and lower the mortality of SARSCoV-2 infection patient as and other cytokine-mediated inflammation by inducing or facilitating the cholinergic antiinflammatory pathway (CAP) [50]. Likewise, activation of the CAP during systemic inflammation down-regulates the assembly and release of inflammatory cytokines [51].

\section{The implication of the hypothesis}

The immune system is unable to adapt at the same rate as microbes, and so pharmaceuticals have been developed to support the body's defenses, such as antibiotics and antiviral. Therefore, attention must be turned to immunomodulators as a therapeutic approach to enhance the efficacy of antimicrobials. Unfortunately, generically enhancing the broad immune response can sometimes worsen the outcome of the disease. By modulating rather than up regulating the immune response via mechanisms such as the cholinergic anti-inflammatory pathway, the damaging positive feedback loops of infection and cytokine storms can be prevented.

From previous data collected from different kinds of literature. I am suggesting that Pyridostigmine (PDG) may improve the number of circulating CD4+ T-cells and reduce the release of inflammatory cytokines. Therefore, lung tissue damage will decrease in COVID-19 infected patient even not need to breathing support, such as mechanical ventilation.

\section{References}

1. Zhou P, Yang XL, Wang XG, Hu B, Zhang L. et al. A pneumonia outbreak associated with a new coronavirus of probable bat origin. Nature. 2020; 579: 270-2730

PubMed: https://pubmed.ncbi.nlm.nih.gov/32015507/

2. Guan WJ, Ni ZY, Hu Y, Liang WH, Ou CQ, He JX, et al. Clinical characteristics of coronavirus disease 2019 in China. N Engl J Med. 2020; 382: 1708-1720.

PubMed: https://pubmed.ncbi.nlm.nih.gov/32109013/

3. Chen N, Zhou M, Dong X, Qu J, Gong F, et al. Epidemiological and clinical characteristics of 99 cases of 2019 novel coronavirus pneumonia in Wuhan, China: a descriptive study. Lancet. 2020; 395: 507-513.

PubMed: https://pubmed.ncbi.nlm.nih.gov/32007143/

4. Xu Z, Shi L, Wang Y, Zhang J, Huang L, et al. Pathological findings of COVID-19 associated with acute respiratory distress syndrome. Lancet Respir Me. 2020; 8: 420-422.

PubMed: https://pubmed.ncbi.nlm.nih.gov/32085846/ 
5. Tracey KJ. Physiology and immunology of the cholinergic antiinflammatory pathway. J Clin Invest. 2007; 117: 289-296.

PubMed: https://www.ncbi.nlm.nih.gov/pmc/articles/PMC1783813/

6. CDC. Severe Acute Respiratory Syndrome. https://www.cdc.gov/sars/ about/fs-sars.html

7. Guan $Y$, Zheng BJ, He YQ, Liu XL, Zhuang ZX, et al. Isolation and characterization of viruses related to the SARS coronavirus from animals in southern China. Science. 2003; 302: 276-278.

PubMed: https://www.ncbi.nlm.nih.gov/pubmed/12958366

8. Lau SK, Woo PC, Li KS, Huang Y, Tsoi HW, et al. Severe acute respiratory syndrome coronavirus-like virus in Chinese horseshoe bats. Proc. Natl Acad Sci USA. 2005; 102: 14040-14045.

PubMed: https://www.ncbi.nlm.nih.gov/pubmed/16169905

9. Li W, Shi Z, Yu M, Ren W, Smith C, et al. Bats are natural reservoirs of SARS-like coronaviruses. Science. 2005; 310: 676-679.

PubMed: https://www.ncbi.nlm.nih.gov/pubmed/16195424

10. Zheng BJ, Wong KH, Zhou J, Wong KL, Young BW, et al. SARSrelated virus predating SARS outbreak, Hong Kong. Emerg Infect Dis. 2004; 10: 176-178.

PubMed: https://www.ncbi.nlm.nih.gov/pmc/articles/PMC3322899/

11. WHO. Middle East Respiratory Syndrome Coronavirus. http://www who.int/ emergencies/mers-cov/en/.

12. Raj VS, Farag EA, Reusken CB, Lamers MM, Pas SD, et al. Isolation of MERS coronavirus from a dromedary camel, Qatar, 2014. Emerg Infect Dis 2014; 20: 1339-1342.

PubMed: https://www.ncbi.nlm.nih.gov/pubmed/25075761

13. Conzade R, Grant R, Malik MR, Elkholy A, et al. Reported Direct and Indirect Contact with Dromedary Camels among Laboratory-Confirmed MERS-CoV Cases. Viruses. 2018; 10: E425.

PubMed: https://www.ncbi.nlm.nih.gov/pubmed/30104551

14. Lu R, Zhao X, Li J, Niu P, Yang B, Wu H, et al. Genomic characterisation and epidemiology of 2019 novel coronavirus: implications for virus origins and receptor binding. Lancet. 2020; 395: 565-574.

PubMed: https://www.ncbi.nlm.nih.gov/pubmed/32007145

15. WHO. Coronavirus disease (COVID-2019) situation reports. 2020 https:// www.who.int/emergencies/diseases/novel-coronavirus-2019/ situationreports

16. Lee $\mathrm{N}$, Hui D, Wu A, Chan P, Cameron P, et al. A major outbreak of severe acute respiratory syndrome in Hong Kong. N Engl J Med. 2003; 348: 1986-1994.

PubMed: https://www.ncbi.nlm.nih.gov/pubmed/12682352

17. Assiri A, Al-Tawfiq JA, Al-Rabeeah AA, Al-Rabiah FA, Al-Hajiar S, et al. Epidemiological, demographic, and clinical characteristics of 47 cases of Middle East respiratory syndrome coronavirus disease from Saudi Arabia: a descriptive study. Lancet Infect Dis. 2013; 13: 752-761. PubMed: https://www.ncbi.nlm.nih.gov/pubmed/23891402

18. Wang H, Xiao X, Lu J, Chen Z, Li K, et al. Factors associated with clinical outcome in 25 patients with avian influenza a (H7N9) infection in Guangzhou, China. BMC Infect Dis. 2016; 16: 534.

PubMed: https://www.ncbi.nlm.nih.gov/pubmed/27716101

19. Huang C, Wang $Y$, Li X, Ren L, Zhao J, et al. Clinical features of patients infected with 2019 novel coronavirus in Wuhan, China. Lancet 2020; 395: 497-506.

PubMed: https://www.ncbi.nlm.nih.gov/pubmed/31986264

20. Tortorici MA, Veesler D. Structural insights into coronavirus entry. Adv Virus Res. 2019; 105: 93-116.

PubMed: https://www.ncbi.nlm.nih.gov/pubmed/31522710
21. Zhang N, Jiang S, Du L. Current advancements and potential strategies in thedevelopment of MERS-CoV vaccines. Expert Rev Vaccines. 2014; 13: 761-774.

PubMed: https://www.ncbi.nlm.nih.gov/pubmed/24766432

22. Xia S, Zhu Y, Liu M, Lan Q, Xu W, et al. Fusion mechanism of 2019$\mathrm{nCoV}$ and fusion inhibitors targeting HR1 domain in spike protein. Cell Mol Immunol. 2020; 1-3.

PubMed: https://www.ncbi.nlm.nih.gov/pubmed/32047258

23. Yu F, Du L, Ojcius DM, Pan C, Jiang S. Measures for diagnosing and treating infections by a novel coronavirus responsible for a pneumonia outbreak originating in Wuhan, China. Microbes Infect. 2020; 22: 74-79. PubMed: https://www.ncbi.nlm.nih.gov/pubmed/32017984

24. de Wilde AH, Snijder EJ, Kikkert M, van Hemert MJ. Host factors in coronavirus replication. Curr Top Microbiol Immunol. 2018; 419: 1-42. PubMed: https://www.ncbi.nlm.nih.gov/pubmed/28643204

25. Sawicki SG, Sawicki DL. Coronavirus transcription: a perspective. Curr Top Microbiol Immunol. 2005; 287: 31-55.

PubMed: https://www.ncbi.nlm.nih.gov/pubmed/15609508

26. Hussain S, Pan J, Chen Y, Yang Y, Xu J, et al. Identification of novel subgenomic RNAs and noncanonical transcription initiation signals of severe acute respiratory syndrome coronavirus. J Virol. 2005; 79: 5288-5295.

PubMed: https://www.ncbi.nlm.nih.gov/pubmed/15827143

27. Perrier A, Bonnin A, Desmarets L, Danneels A, Goffard A, et al. The C-terminal domain of the MERS coronavirus $M$ protein contains a trans- Golgi network localization signal. J Biol Chem. 2019; 294 14406-14421.

PubMed: https://www.ncbi.nlm.nih.gov/pubmed/31399512

28. Wu F, Zhao S, Yu B, Chen YM, Wang W, et al. A new coronavirus associated with human respiratory disease in China, Nature. 2020; 579: 265-269. PubMed: https://www.ncbi.nlm.nih.gov/pubmed/32015508

29. Jeffers SA, Tusell SM, Gillim-Ross L, et al. CD209L (L-SIGN) is a receptor for severe acute respiratory syndrome coronavirus, Proc. Natl. Acad. Sci. U. S. A. 2004; 101: 15748-15753

PubMed: https://www.ncbi.nlm.nih.gov/pubmed/15496474

30. Vacchelli E, Galluzzi L, Eggermont A. et al. Trial Watch: immunostimulatorycytokines. Oncoimmunology. 2012; 1: 493-506.

31. Dendorfer U. Molecular biology of cytokines. Artif Organs. 1996; 20 : 437-444.

PubMed: https://www.ncbi.nlm.nih.gov/pubmed/8725624

32. Wang D, Hu B, Hu C, Zhu F, Liu X, et al. Clinical Characteristics of 138 Hospitalized Patients With 2019 Novel Coronavirus-Infected Pneumonia in Wuhan, China. JAMA. 2020; 323: 1061-1069. PubMed: https://www.ncbi.nlm.nih.gov/pubmed/32031570

33. Todd NW, Luzina IG, Atamas SP. Molecular and cellular mechanisms of pulmonary fibrosis. Fibrogenesis Tissue Repair. 2012; 5: 11 PubMed: https://www.ncbi.nlm.nih.gov/pubmed/22824096

34. Chen C, Zhang XR, Ju ZY, He WF. Advances in the research of cytokine storm mechanism induced by Corona Virus Disease 2019 and the corresponding immunotherapies. Zhonghua Shaoshang Zazhi. 2020; 36: E005.

PubMed: https://www.ncbi.nlm.nih.gov/pubmed/32114747

35. Liu Y, Zhang C, Huang F, Yang Y, Wang F, et al. 2019-novel coronavirus (2019-nCoV) infections trigger an exaggerated cytokine response aggravating lung injury. 2020. http://www.chinaxiv.org/abs/202

36. Williams AE, Chambers RC. The mercurial nature of neutrophils: still an enigma in ARDS? Am J Physiol Lung Cell Mol Physiol. 2014; 306: L217-230.

PubMed: https://www.ncbi.nlm.nih.gov/pubmed/24318116 
37. Cameron MJ, Bermejo-Martin JF, Danesh A, et al. Human immunopathogenesis of severe acute respiratory syndrome (SARS), Virus Res. 2008; 133: 13-19.

PubMed: https://www.ncbi.nlm.nih.gov/pubmed/17374415

38. Min CK, Cheon S, Ha NY, Sohn KM , Kim Y, et al. Comparative and kinetic analysis of viral shedding and immunological responses in MERS patients representing a broad spectrum of disease severity. Sci Rep. 2016; 6: 25359.

PubMed: https://pubmed.ncbi.nlm.nih.gov/27146253/

39. Xu Z, Shi L, Wang Y, Zhang J, Huang L, et al. Pathological findings of COVID-19 associated with acute respiratory distress syndrome, Lancet Resp Med. 2020; 8: 420-422.

PubMed: https://www.ncbi.nlm.nih.gov/pubmed/32085846

40. Coggle JE, Lambert BE, Moores SR. Radiation effects in the lung Environ Health Perspect. 1986; 70: 261-291.

PubMed: https://www.ncbi.nlm.nih.gov/pubmed/3549278

41. Féréol S, Fodil R, Pelle G, Louis B, Isabey D. Cell mechanics of alveolar epithelial cells (AECs) and macrophages (AMs). Respir Physiol Neurobiol. 2008; 163: 3-16.

PubMed: https://www.ncbi.nlm.nih.gov/pubmed/18565804

42. Fehrenbach H. Alveolar epithelial type II cell: defender of the alveolus revisited. Respir Res. 2001; 2: 33-46.

PubMed: https://www.ncbi.nlm.nih.gov/pmc/articles/PMC59567/

43. Tian S, Hu W, Niu L, Liu $\mathrm{H}, \mathrm{Xu} \mathrm{H}$, et al. Pulmonary Pathology of Early-Phase 2019 Novel Coronavirus (COVID-19) Pneumonia in Two Patients With Lung Cancer. J Thorac Oncol. 2020; 5: 700-704. PubMed: https://www.ncbi.nlm.nih.gov/pubmed/32114094

44. Xu Z, Shi L, Wang Y, Zhang J, Huang L, et al. Pathological findings of COVID-19 associated with acute respiratory distress syndrome. Lancet Respir Med. 2020: 8: 420-422.

PubMed: https://www.ncbi.nlm.nih.gov/pubmed/32085846

45. Tian S, Hu W, Niu L, Liu H, Xu H, et al. Pulmonary pathology of early phase 2019 novel coronavirus (COVID-19) pneumonia in two patients with lung cancer. J Thorac Oncol. 2020; 15: 700-704.

PubMed: https://www.ncbi.nlm.nih.gov/pmc/articles/PMC7128866/

46. Tracey KJ. Physiology and immunology of the cholinergic antiinflammatory pathway. J Clin Invest. 2007; 117: 289-296.

PubMed: https://www.ncbi.nlm.nih.gov/pmc/articles/PMC1783813/

47. Paiardini M, Müller-Trutwin M. HIV-associated chronic immune activation. Immunol Rev. 2013: 254: 78-101.

PubMed: https://www.ncbi.nlm.nih.gov/pubmed/23772616

48. Moncunill G, Negredo E, Bosch L, Vilarrasa J, Witvrouw M, Llano A, et al. Evaluation of the anti-HIV activity of statins. AIDS. 2005; 19: 1697-700. PubMed: https://www.ncbi.nlm.nih.gov/pubmed/16184043

49. Valdés-Ferrer SI, Crispín JC, Belaunzarán PF, Cantú-Brito CG, Sierra-Madero J, et al. Acetylcholine-esterase inhibitor pyridostigmine decreases T cell overactivation in patients infected by HIV. AIDS Res Hum Retroviruses. 2009; 25: 749-755.

PubMed: https://www.ncbi.nlm.nih.gov/pubmed/19645607

50. Borovikova LV, Ivanova S, Zhang M, Yang H, Botchkina GI, Watkins $\mathrm{LR}$, et al. Vagus nerve stimulation attenuates the systemic inflammatory response to endotoxin. Nature. 2000; 405: 458-462. PubMed: https://www.ncbi.nlm.nih.gov/pubmed/10839541

51. Pavlov VA, Tracey KJ. Neural regulation of immunity: molecular mechanisms and clinical translation. Nat Neurosci. 2017; 20: 156-166. PubMed: https://www.ncbi.nlm.nih.gov/pubmed/28092663 